\title{
The clinical spectrum of ocular bartonellosis: a retrospective study at a tertiary centre in Malaysia
}

\author{
Michele Shi-Ying Tey ${ }^{*}$ (D, Gayathri Govindasamy and Francesca Martina Vendargon
}

\begin{abstract}
Background: Cat scratch disease (CSD) is a systemic illness caused by the gram-negative bacillus, Bartonella henselea, which can occasionally involve the ocular structures. The objective of this study is to evaluate the various clinical presentations of ocular bartonellosis at our institution. A retrospective review of the clinical records of 13 patients (23 eyes) with ocular manifestations of Bartonella infections over a 3-year period between January 2016 to December 2018 was undertaken at our institution.

Results: The diagnosis was made based on clinical findings and in addition, with the support of the evidence of Bartonella hensalae lgG and/or lgM. Small retinal white lesions were the most common ocular findings in this series of patients ( $82.6 \%$ of eyes, $76.9 \%$ of patients). Neuroretinitis was the second most common finding ( $47.8 \%$ of eyes, $69.2 \%$ of patients), followed by exudative retinal detachment involving the macula (34.8\% of eyes, $53.8 \%$ of patients) and Parinaud's oculoglandular syndrome (17.4\% of eyes, $23.1 \%$ of patients). Other findings like isolated optic disc oedema without macular star ( $8.7 \%$ of eyes, $15.4 \%$ of patients) and vitritis (4.3\% of eyes, $7.7 \%$ of patients) were also observed. Ten patients (76.9\%) had bilateral ocular involvement. Most of the patients were young, immunocompetent and had systemic symptoms like fever prior to their ocular symptoms. The visual acuity (VA) at initial presentation ranged from 6/6 to hand movement (mean, 6/20), and at final visit 6/6 to 6/60, (mean, 6/9). $91.7 \%$ of patients were treated with antibiotics. Only 2 patients received oral corticosteroids together with antibiotics due to very poor vision on presentation. The visual prognosis of ocular bartonellosis is generally good with $16(88.9 \%)$ of 23 eyes having VA of $6 / 12$ or better at final follow-up visit.

Conclusion: Small foci of retinal white lesions were the most common manifestation of ocular bartonellosis in this series, followed by neuroretinitis, though an array of other ocular findings may also occur. Therefore, we should consider bartonella infection as a possible differential diagnosis in those patients.
\end{abstract}

Keywords: Ocular bartonellosis, Cat scratch disease, Bartonella hensalae, Neuroretinitis, Parinaud's oculoglandular syndrome

\section{Background}

Cat scratch disease (CSD) is a systemic illness caused by the gram-negative bacillus, Bartonella henselea [1]. The disease is transmitted by the bite or scratch of an infected animal, often a young cat or kitten [1]. The disease commonly affects children and young adults and is

* Correspondence: micheletey23@gmail.com

Department of Ophthalmology, Hospital Sultanah Aminah, Johor Bahru, Johor, Malaysia

Springer Open usually self-limiting in immunocompetent individuals. Typical CSD is characterized by lymphadenopathy, fever and flu-like symptoms though the pathological response to the infection can differ greatly with the status of the host immune system [2]. It may range from mild to severe, and can result in a focal suppurative response, a multifocal angioproliferative response (bacillary angiomatosis), endocarditis or meningoencephalitis, especially in the immunocompromised [2-4]. 
Numerous ocular manifestations of Bartonella infections can occur in those infected. The posterior segment findings reported in literature include neuroretinitis, optic neuritis, focal retinitis, choroiditis, chorioretinitis, exudative maculopathy, serous retinal detachment and vitritis [5-7]. Ocular complications like branch retinal artery occlusion, macular hole and peripapillary angiomatosis had also been described [8-10]. Conjunctival manifestations such as Parinaud's oculoglandular syndrome and nonspecific follicular conjunctivitis were also reported [8-11].

This study aims to examine the various ocular presentation, management and visual outcome of ocular bartonellosis. In this case series, we included only patients whose clinical diagnosis of ocular bartonellosis were supported by laboratory evidence of $B$. Hensalae infection.

\section{Methods}

We performed a retrospective review of clinical records of 13 patients (23 eyes) with ocular bartonellosis treated in Hospital Sultanah Aminah Johor Bahru, a tertiary centre in southern region of Malaysia, over a 3-year period, between January 2016 and December 2018.

The selection criteria for this study include the diagnosis of ocular bartonellosis by clinical examinations and supported by at least a single positive serology test for $B$. Hensalae. Serology tests were all performed via immunofluorescence assay (IFA) in the Bacteriology Unit, Institute for Medical Research, Ministry of Health Malaysia. The cut off value was $\geq 1: 12$ for IgM and/or $\geq$ 1:64 for IgG using a commercial kit to detect Bartonella henselae and Bartonella quintana.

We collected various data including demographic details, systemic comorbidities, systemic symptoms prior to ocular presentation, history of cats contact or cat scratch, B. Hensalae serology results, laterality, visual acuity (VA) on initial presentation and at final visit, ocular findings, spectral domain optical coherence tomography (SD-OCT) findings, follow-up duration and the treatment received by patients. The VA of patients were recorded using the standard Snellen chart at $6 \mathrm{~m}^{\prime}$ distance.

All patients had complete ophthalmological examination, fundus photography and SD-OCT imaging done. The clinical records and images were reviewed by trained ophthalmologists at our institution for evidence of disc oedema, macular star, retinitis or choroiditis infiltrates, intraretinal fluid (IRF), subretinal fluid (SRF) and other findings.

The study was done in accordance to the Malaysian Good Clinical Practice (MGCP) 4th edition 2018 and was registered in the National Medical Research Register (NMRR).

\section{Result}

A total of 13 patients (23 eyes), 9 females and 4 males were diagnosed with ocular bartonellosis within the study period. The demographic data and other clinical information of our study interest are summarized in Tables 1 and 2. The mean age of presentation is 27.5 (range, 11-54 years). There were $5(38.5 \%)$ paediatric patients $(\leq 16$ years old). Eleven patients $(84.6 \%)$ had no pre-existing systemic co-morbidities. Systemic symptoms of fever, flu-like symptoms and malaise preceding the development of ocular symptoms were common, and were reported in 11 patients $(84.6 \%)$. Ten patients (76.9\%) were able to recall cat scratch or history of exposure to cats or kittens. In the remaining 3 patients (231\%), though no definite exposure was reported, they had serological evidence of Bartonella infection. Ten patients (76.9\%) presented with bilateral eye involvement, either simultaneous or sequentially, while 3 patients $(23.1 \%)$ had unilateral eye involvement throughout the follow-up duration.

The mean follow-up time was 12.8 weeks (range, 2-36 weeks). Three patients were lost to follow-up and excluded from final VA analysis. The initial presenting VA ranged from 6/6 to hand movement (mean 6/20) and at final follow-up visit $6 / 6$ to $6 / 60$ (mean 6/9), as shown in Table 2. Twelve of the 13 patients (92.3\%) were treated with systemic antibiotics. Eight patients $(61.5 \%)$ were treated with doxycycline, three patients (23.1\%) with ciprofloxacin (23.1\%), one patient $(7.7 \%)$ with azithromycin and one patient (7.7\%) with erythromycin. Two patients had switched antibiotics during the course of the treatment due to suspected adverse reactions to the initial antibiotics. The average duration of systemic antibiotics were 4-6 weeks for posterior segment involvement and 1-2 weeks for Parinaud's oculoglandular syndrome. In addition, two patients (15.4\%) were treated with oral corticosteroids due to very poor presenting vision. The visual prognosis of ocular bartonellosis is generally good with 16 (88.9\%) of 23 eyes having VA of $6 / 12$ or better at final follow-up visit (excluding those who were lost to follow-up).

Ocular findings of our patients are listed in Table 2. Ten out of the 13 patients $(76.9 \%)$ presented with posterior segment manifestations, while 3 out of the 13 patients $(23.1 \%)$ had Parinaud's oculoglandular syndrome without posterior segment involvement. Small foci of retinal white lesions were the most common manifestations, occurring in 19 eyes (82.6\%) (Fig. 1a-d). Neuroretinitis was the second most common finding, seen in 11 eyes $(47.8 \%)$ (Fig. 2a-b). This is followed by exudative retinal detachment (SRF under fovea evident on SDOCT) in 8 eyes $(34.8 \%)$ and Parinaud's oculoglandular syndrome in 4 eyes (17.4\%) (Fig. 3a-c). Other less common findings were isolated optic disc oedema without 
Table 1 Patients' demographic data, systemic comorbidities, systemic symptoms, exposure to cats/kittens and serology for $B$. hensalae

\begin{tabular}{|c|c|c|c|c|c|}
\hline $\begin{array}{l}\text { Patient No., sex, } \\
\text { age (yrs) }\end{array}$ & $\begin{array}{l}\text { Systemic } \\
\text { comorbidities }\end{array}$ & Systemic symptoms & $\begin{array}{l}\text { Exposure to cats } \\
\text { /kittens }\end{array}$ & Serology for B. hensalae & \\
\hline $1, F, 36$ & - & Fever $\times 2$ wks & Yes & $\begin{array}{l}\lg M \geq 1: 24 \\
\lg G \geq 1: 128\end{array}$ & \\
\hline $2, F, 54$ & Diabetes, hypertension & Fever $\&$ malaise $\times 3$ wks & Yes & $\begin{array}{l}\lg M \geq 1: 24 \\
\lg G \geq 1: 128\end{array}$ & \\
\hline $3, M, 28$ & - & - & Yes & $\begin{array}{l}\lg M \geq 1: 24 \\
\lg G \geq 1: 128\end{array}$ & \\
\hline $4, F, 12$ & - & Fever $\times 2$ wks & Yes & $\begin{array}{l}\lg M \geq 1: 24 \\
\lg G \geq 1: 128\end{array}$ & \\
\hline $5, F, 50$ & - & Fever $\times 1$ wk & Unsure & $\begin{array}{l}\lg M \geq 1: 24 \\
\lg G \geq 1: 128\end{array}$ & \\
\hline $6, M, 11$ & - & Fever \& flu-like symptoms $\times 1$ wk & Yes & $\begin{array}{l}\lg M \geq 1: 24 \\
\lg G \geq 1: 128\end{array}$ & \\
\hline $7, F, 27$ & - & Fever \& flu-like symptoms $\times 1$ wk & Yes & $\begin{array}{l}\lg M \geq 1: 24 \\
\lg G \geq 1: 128\end{array}$ & \\
\hline $8, F, 12$ & - & $\begin{array}{l}\text { Fever } \times 5 \text { days, left submandibular } \\
\& \text { pre-auricular lymphadenopathy }\end{array}$ & Yes & $\begin{array}{l}\lg M \geq 1: 24 \\
\lg G \geq 1: 128\end{array}$ & \\
\hline $9, F, 38$ & Renal failure & - & Unsure & $\begin{array}{l}\lg M \geq 1: 12 \\
\lg G \geq 1: 64\end{array}$ & $\begin{array}{l}\text { Repeated: } \\
\operatorname{lgM} \geq 1: 12 \\
\operatorname{lgG} \geq 1: 256\end{array}$ \\
\hline $10, F, 11$ & - & $\begin{array}{l}\text { Fever } \times 1 \text { wk., left pre-auricular } \\
\& \text { cervical lymphadenopathy }\end{array}$ & Yes & $\begin{array}{l}\lg M<1: 12 \text { (negative) } \\
\lg G \geq 1: 128\end{array}$ & \\
\hline $11, M, 15$ & - & $\begin{array}{l}\text { Fever } \times 5 \text { days, right submandibular } \\
\text { lymphadenopathy }\end{array}$ & Yes & $\begin{array}{l}\lg M \geq 1: 24 \\
\lg G<1: 64 \text { (negative) }\end{array}$ & \\
\hline $12, F, 34$ & - & Fever $\times 1$ wk & Unsure & $\begin{array}{l}\lg M<1: 12 \text { (negative) } \\
\lg G \geq 1: 64\end{array}$ & $\begin{array}{l}\text { Repeated: } \\
\lg M<1: 12 \\
\lg \mathrm{l} \geq 1: 256\end{array}$ \\
\hline $13, M, 30$ & - & Fever $\times 1$ wk & Yes & $\begin{array}{l}\lg G \geq 1: 24 \\
\lg M \geq 1: 128\end{array}$ & \\
\hline
\end{tabular}

$F$ Female, $M$ Male

macular star, occurring in 2 eyes $(8.7 \%)$ and vitritis which occurred in 1 eye (4.3\%). SD-OCT imaging was done for all the eyes with posterior segment involvement, and it was found that among them, 13 eyes (68.4\%) have hyperreflective spots within the outer plexiform layer (OPL), corresponding to the stellate macular hard exudates seen clinically and 8 eyes (42.1\%) have SRF under fovea causing serous elevation of the neurosensory retina i.e. exudative retinal detachment.

\section{Discussion}

Similar to earlier retrospective studies, the patients in our series were young (mean, 27.5 years) $[9,12,13]$. Simultaneous or sequential bilateral eye involvement were more common in our series (76.9\% of patients). This is in contrast to prior reports, wherein unilateral eye involvement was reported to be more common $[1,5]$. Though there were 3 patients who were unsure if they had contact with cats or kittens prior to the ocular presentation, they had clinical and serological evidence of bartonella infection. Some reports have shown that apart from cats, animals like dogs, monkeys and porcupines may harbour the agent [14]. Cat fleas (Ctenocephalides felis) may also play a role as an arthropod vector [14].

The ocular findings in our series of patients are similar to the one reported by Solley et al. (1999) which described retinal or choroidal white lesions to be the primary ocular manifestations of CSD and neuroretinitis as the second most common ocular presentation [1]. However, there are studies that reported neuroretinitis as the commonest ocular manifestation, such as the one by Ormerod et al. (1999) [8]. Neuroretinitis is a vasculitic process within the optic nerve head coupled with secondary stellate macular exudates [15]. The optic disc swelling is known to precede stellate exudation by $2-4$ weeks [9]. There have been few reported cases of bilateral neuroretinitis $[15,16]$. In our series, only 2 patients had the rare presentation of bilateral neuroretinitis (Fig. 4a-d), similar to several other studies that had reported neuroretinitis to be commonly unilateral $[5,8]$. We observed in our series that 7 of 10 patients (70\%) with posterior segment manifestation of ocular bartonellosis presents with neuroretinitis in one eye, coupled with small foci of white retinal or choroidal lesions in both 
Table 2 Laterality, initial and final VA, ocular manifestations, OCT findings, follow-up duration and treatment

\begin{tabular}{|c|c|c|c|c|c|c|c|c|}
\hline $\begin{array}{l}\text { Patient } \\
\text { No. }\end{array}$ & Lat & Eye & $\begin{array}{l}\text { Initial } \\
\text { VA }\end{array}$ & $\begin{array}{l}\text { Final } \\
\text { VA }\end{array}$ & Ocular manifestations & OCT findings & $\begin{array}{l}\text { Follow } \\
\text { up }\end{array}$ & Treatment \\
\hline 1 & $\mathrm{BE}$ & OS & $\begin{array}{l}6 / 7.5 \\
6 / 20\end{array}$ & $\begin{array}{l}6 / 6 \\
6 / 6\end{array}$ & $\begin{array}{l}\text { LE neuroretinits \& flame haemorrhage (at optic disc } \\
\text { margin), BE small retinal white lesions }\end{array}$ & $\begin{array}{l}\text { LE SRF under macula \& } \\
\text { hyperreflective foci within } \\
\text { OPL (HE) }\end{array}$ & 23 wks & $\begin{array}{l}\text { Doxycycline } \times \\
6 w k s\end{array}$ \\
\hline 2 & $\mathrm{BE}$ & $\begin{array}{l}\text { OS } \\
\text { OD }\end{array}$ & $\begin{array}{l}6 / 60 \\
6 / 6\end{array}$ & $\begin{array}{l}6 / 60 \\
6 / 7.5\end{array}$ & $\begin{array}{l}\text { RE neuroretinitis, LE flame haemorrhage (at optic } \\
\text { disc margin), BE small retinal white lesions }\end{array}$ & $\begin{array}{l}\text { RE SRF under macula \& } \\
\text { hyperreflective foci within } \\
\text { OPL (HE) }\end{array}$ & 16 wks & $\begin{array}{l}\text { Ciprofloxacin } \times 5 \\
\text { wks } \\
\text { Oral Prednisolone } \\
\times 1 \mathrm{mo}\end{array}$ \\
\hline 3 & $\mathrm{BE}$ & $\begin{array}{l}\text { OS } \\
\text { OD }\end{array}$ & $\begin{array}{l}6 / 15 \\
6 / 6\end{array}$ & - & $\begin{array}{l}\text { RE neuroretinitis \& flame haemorrhage (at optic disc } \\
\text { margin), LE one small flame haemorrhage at } \\
\text { supratemporal arcade, BE small retina white lesions }\end{array}$ & $\begin{array}{l}\text { RE hyperreflective foci } \\
\text { within OPL (HE), IRF (CMO) } \\
\text { \& SRF under macula }\end{array}$ & - & $\begin{array}{l}\text { Doxycycline } \times 6 \\
\text { wks }\end{array}$ \\
\hline 4 & $\mathrm{BE}$ & $\begin{array}{l}\text { OS } \\
\text { OD }\end{array}$ & $\begin{array}{l}\text { CF } \\
6 / 9\end{array}$ & $\begin{array}{l}6 / 9 \\
6 / 6\end{array}$ & $\begin{array}{l}\text { RE neuroretinitis, small flame haemorrhage (at optic } \\
\text { disc margin) with marked retinal vessels tortuosity \& } \\
\text { dilatation, BE small retinal white lesions }\end{array}$ & $\begin{array}{l}\text { RE SRF under macula \& } \\
\text { hyperreflective foci within } \\
\text { OPL (HE) }\end{array}$ & 9 wks & $\begin{array}{l}\text { Doxycycline } \times 9 \\
\text { days Azithromycin } \\
\times 4 \text { wks } \\
\text { Oral Prednisolone } \\
\times 1 \text { mo }\end{array}$ \\
\hline 5 & $\mathrm{BE}$ & $\begin{array}{l}\text { OS } \\
\text { OD }\end{array}$ & $\begin{array}{l}6 / 6 \\
6 / 12\end{array}$ & $\begin{array}{l}6 / 6 \\
6 / 6\end{array}$ & LE neuroretinitis, BE small retinal white lesions & $\begin{array}{l}\text { RE hyperreflective RNFL foci } \\
\text { (retinitis), hyperreflective } \\
\text { foci within OPL (HE) \& IRF }\end{array}$ & 7 wks & $\begin{array}{l}\text { Ciprofloxacin } \times 3 \\
\text { days } \\
\text { Augmentin } \times \\
2 \text { wks }\end{array}$ \\
\hline 6 & $\mathrm{BE}$ & $\begin{array}{l}\text { OS } \\
\text { OD }\end{array}$ & $\begin{array}{l}6 / 30 \\
H M\end{array}$ & - & $\begin{array}{l}\text { BE neuroretinitis and flame haemorrhages (at BE } \\
\text { optic disc margin), BE small retina white lesions with } \\
\text { marked retinal vessels tortuosity \& dilatation }(L>R)\end{array}$ & $\begin{array}{l}\text { BE SRF under macula }(L>R) \\
\& \text { hyperreflective foci within } \\
\text { OPL (HE) }\end{array}$ & - & $\begin{array}{l}\text { Doxycycline } \times 2 \\
\text { wks }\end{array}$ \\
\hline 7 & $\mathrm{BE}$ & $\begin{array}{l}\text { OS } \\
\text { OD }\end{array}$ & $\begin{array}{l}1 / 60 \\
6 / 9\end{array}$ & $\begin{array}{l}6 / 18 \\
6 / 9\end{array}$ & $\begin{array}{l}\text { RE neuroretinitis, flame haemorrhage (at optic disc } \\
\text { margin) with marked retinal vessels tortuosity \& } \\
\text { dilatation, BE small retinal white lesions }\end{array}$ & $\begin{array}{l}\text { RE IRF (CMO), SRF under } \\
\text { macula \& hyperreflective } \\
\text { foci within OPL (HE) }\end{array}$ & 6 wks & $\begin{array}{l}\text { Doxycycline } \times 6 \\
\text { wks }\end{array}$ \\
\hline 8 & $\mathrm{BE}$ & $\begin{array}{l}\text { OS } \\
\text { OD }\end{array}$ & $\begin{array}{l}6 / 9 \\
6 / 9\end{array}$ & $\begin{array}{l}6 / 9 \\
6 / 9\end{array}$ & $\begin{array}{l}\text { BE Large granulomatous lesions at palpebral } \\
\text { conjunctivae }\end{array}$ & - & 16 wks & $\begin{array}{l}\text { Erythromycin } \times 2 \\
\text { wks }\end{array}$ \\
\hline 9 & $\mathrm{BE}$ & $\begin{array}{l}\text { OS } \\
\text { OD }\end{array}$ & $\begin{array}{l}6 / 9 \\
6 / 9\end{array}$ & $\begin{array}{l}6 / 9 \\
6 / 9\end{array}$ & $\begin{array}{l}\text { BE neuroretinitis (partial macular star) \& BE small } \\
\text { retinal white lesions }\end{array}$ & $\begin{array}{l}\text { BE hyperreflective foci } \\
\text { within OPL (HE) }\end{array}$ & 36 wks & - \\
\hline 10 & LE & $\begin{array}{l}\text { OS } \\
\text { OD }\end{array}$ & $\begin{array}{l}6 / 9 \\
6 / 9\end{array}$ & - & LE granulomatous follicular conjunctivitis & - & - & $\begin{array}{l}\text { Doxycycline } \times 1 \\
\text { wk }\end{array}$ \\
\hline 11 & RE & $\begin{array}{l}\text { OS } \\
\text { OD }\end{array}$ & $\begin{array}{l}6 / 6 \\
6 / 6\end{array}$ & $\begin{array}{l}6 / 6 \\
6 / 6\end{array}$ & RE granulomatous follicular conjunctivitis & - & $2 w k s$ & $\begin{array}{l}\text { Doxycycline } \times 1 \\
\text { wk }\end{array}$ \\
\hline 12 & LE & $\begin{array}{l}\text { OS } \\
\text { OD }\end{array}$ & $\begin{array}{l}6 / 6 \\
6 / 9\end{array}$ & $\begin{array}{l}6 / 6 \\
6 / 9\end{array}$ & $\begin{array}{l}\text { LE optic disc swelling with vitritis \& LE small retinal } \\
\text { white lesions }\end{array}$ & $\begin{array}{l}\text { LE PVD with hyperreflective } \\
\text { spots in vitreous (vitritis) \& } \\
\text { swollen LE ONH }\end{array}$ & 5 wks & $\begin{array}{l}\text { Ciprofloxacin } \times 1 \\
\text { mo }\end{array}$ \\
\hline 13 & $\mathrm{BE}$ & $\begin{array}{l}\text { OS } \\
\text { OD }\end{array}$ & $\begin{array}{l}6 / 6 \\
6 / 38\end{array}$ & $\begin{array}{l}6 / 6 \\
6 / 6\end{array}$ & LE neuroretinitis, BE small retinal white lesions & $\begin{array}{l}\text { LE SRF under macula \& BE } \\
\text { hyperreflective foci within } \\
\text { OPL (HE) }\end{array}$ & $8 w k s$ & $\begin{array}{l}\text { Doxycycline } \times 6 \\
\text { wks }\end{array}$ \\
\hline
\end{tabular}

Lat Laterality, BE Both eyes, RE Right eye, LE Left eye, OS Right eye, OD Left eye, CF Counting finger, HM Hand movement, OCT Optical coherence tomography, SRF Subretinal fluid, OPL Outer plexiform layer, HE Hard exudate, CMO Cystoid macular oedema, IRF Intraretinal fluid, PVD \{posterior vitreous detachment, ONH Optic nerve head

of the eyes. In addition, eight eyes (34.8\%) was found to have exudative retinal detachment, evident by presence of SRF under fovea on SD-OCT (Figs. 2b, 4c-d and 6b, d). Peripapillary serous retinal detachment as a result of optic disc oedema in Bartonella patients has been reported to be common yet underrecognized [17]. Furthermore, six patients had flame-shaped haemorrhages at the margin of the oedematous optic disc. Habot-Wilner Z et al. (2011) had reported clusters of telangiectatic vessels on the optic nerve edge with hyper-fluorescence and leakage when fluorescein angiogram was performed [18]. These findings may be explained by the predilection of $B$. henselae towards the vascular endothelium [19]. Likewise, patients with markedly swollen optic disc tend to have more tortuous and dilated retinal vessels and correspondingly more extensive macular exudates, SRF and poorer VA (Fig. 4a-b). Collectively, these findings provide clues to help the clinician in diagnosing an ocular bartonella infection.

Of note, several cases showed interesting findings. Patient no. 6 had massive optic nerve head swelling with substantial SRF that caused marked serous detachment of the macular (Fig. 4a-d). The fundamental pathophysiology of this occurrence has been described as transudation from the inflamed optic nerve head $(\mathrm{ONH})$ into the subretinal space of an apparently normal macula [19]. On the other hand, patient no. 12 had optic disc oedema 


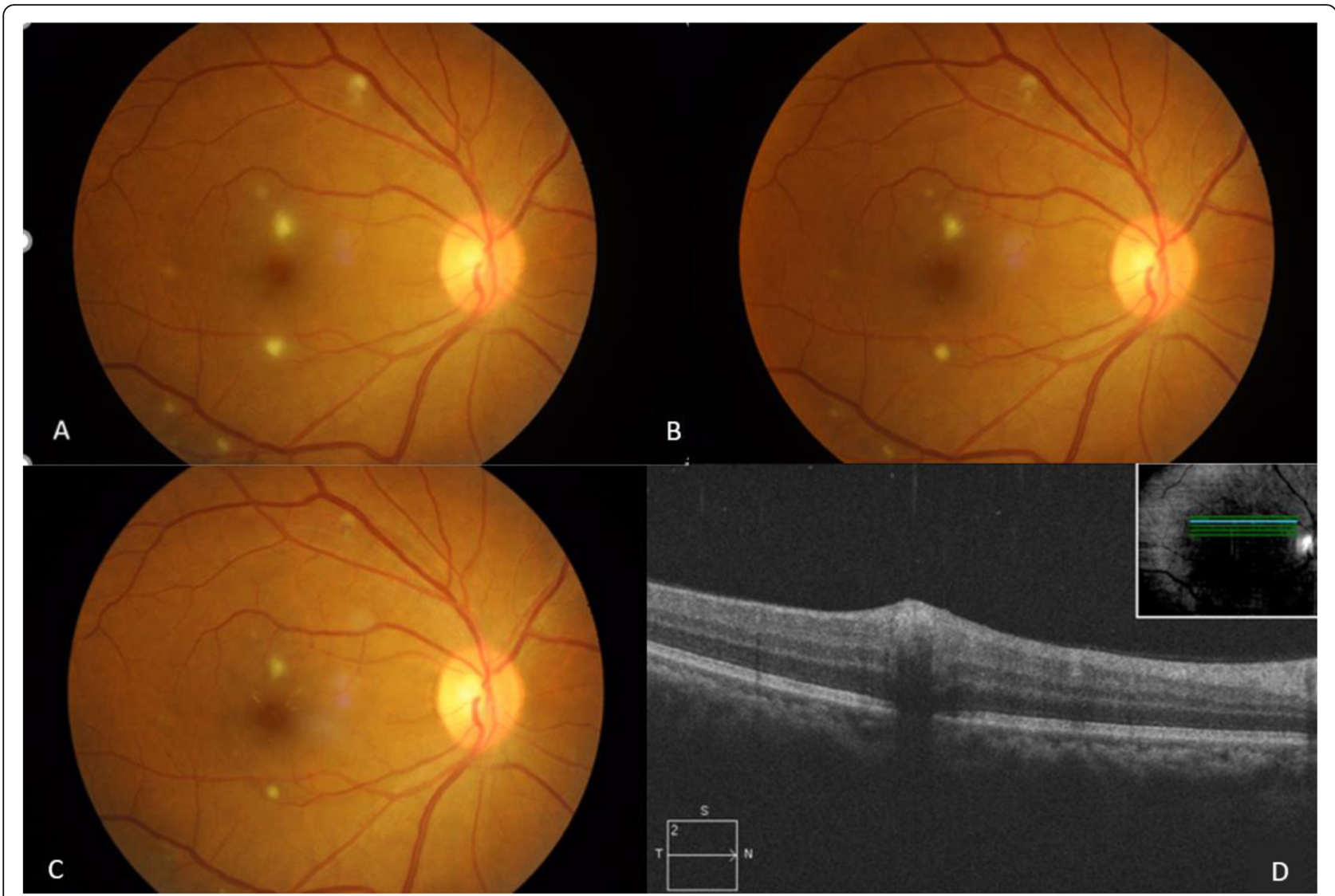

Fig. 1 Patient no. 5. a, b and c Colour fundus photograph of the right eye: multiple small foci of yellow-white retinitis lesions. The lesions' borders become more well-defined and the sizes reduce over time. $\mathbf{d}$ SD-OCT of the same eye: cross section superior to the fovea across the foci of retinitis appear as hyperreflectivity in the inner retinal layers while casting a shadow below it
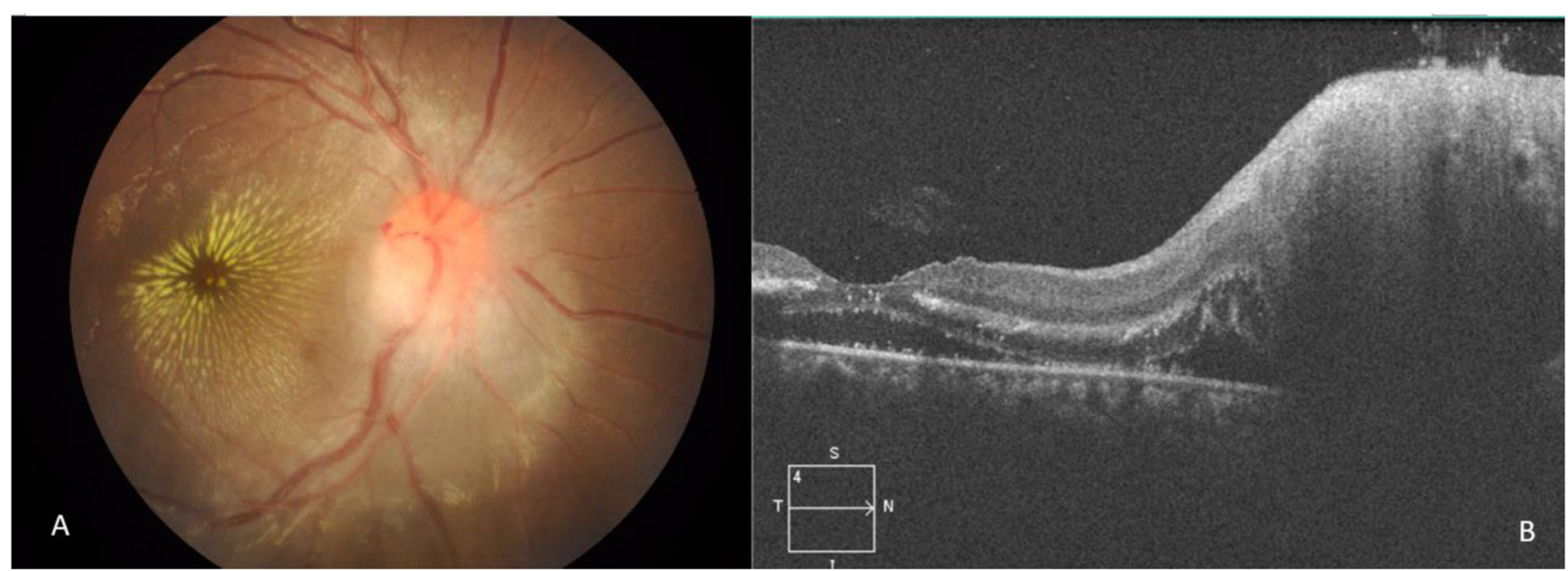

Fig. 2 Patient no. 4. a Colour fundus photograph of the right eye: peripapillary retinal oedema with prominent macular star (typical neuroretinitis), splinter haemorrhage near the margin of the disc with tortuous and markedly dilated retinal vessels. b SD-OCT of the same eye: showing swollen ONH with SRF causing exudative retinal detachment involving the fovea. Hyperreflective spots within the OPL correspond to the macular star clinically 


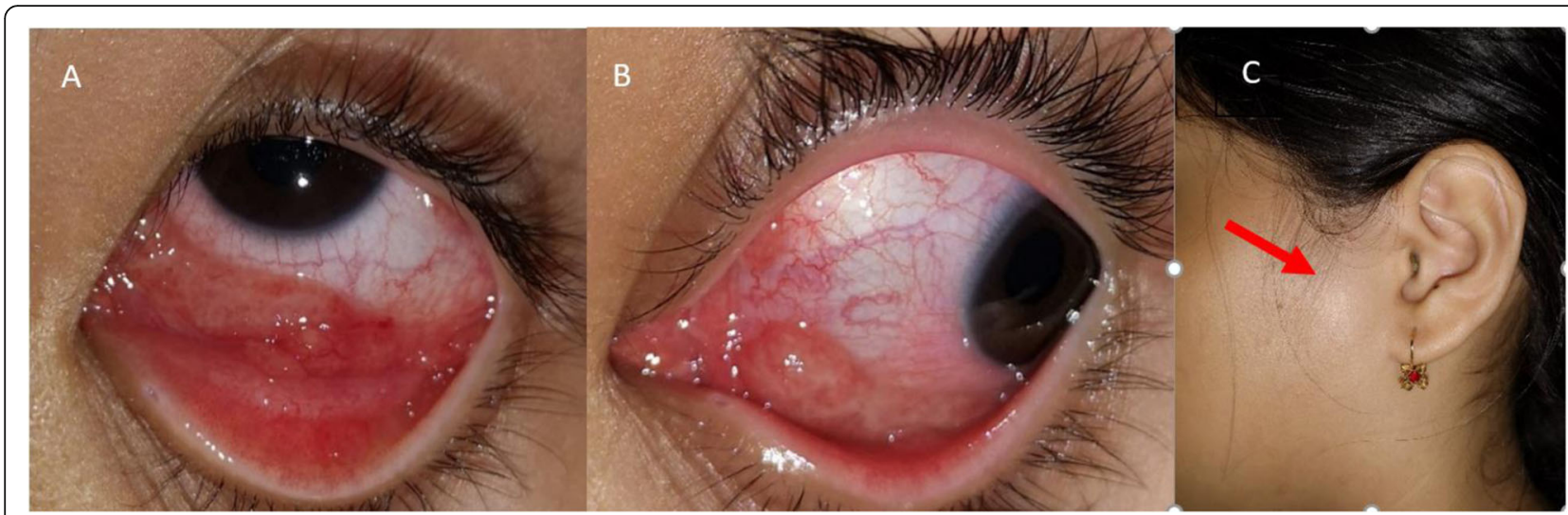

Fig. 3 Patient no. 10. A 11-year old girl with history of cat scratch presented with left eye redness, fever, cervical and pre-auricular lymph nodes swelling. $\mathbf{a}$ and $\mathbf{b}$ Granulomatous nodules on left lower tarsal and bulbar conjunctivae. $\mathbf{c}$ Red arrow showing pre-auricular lymph node enlargement

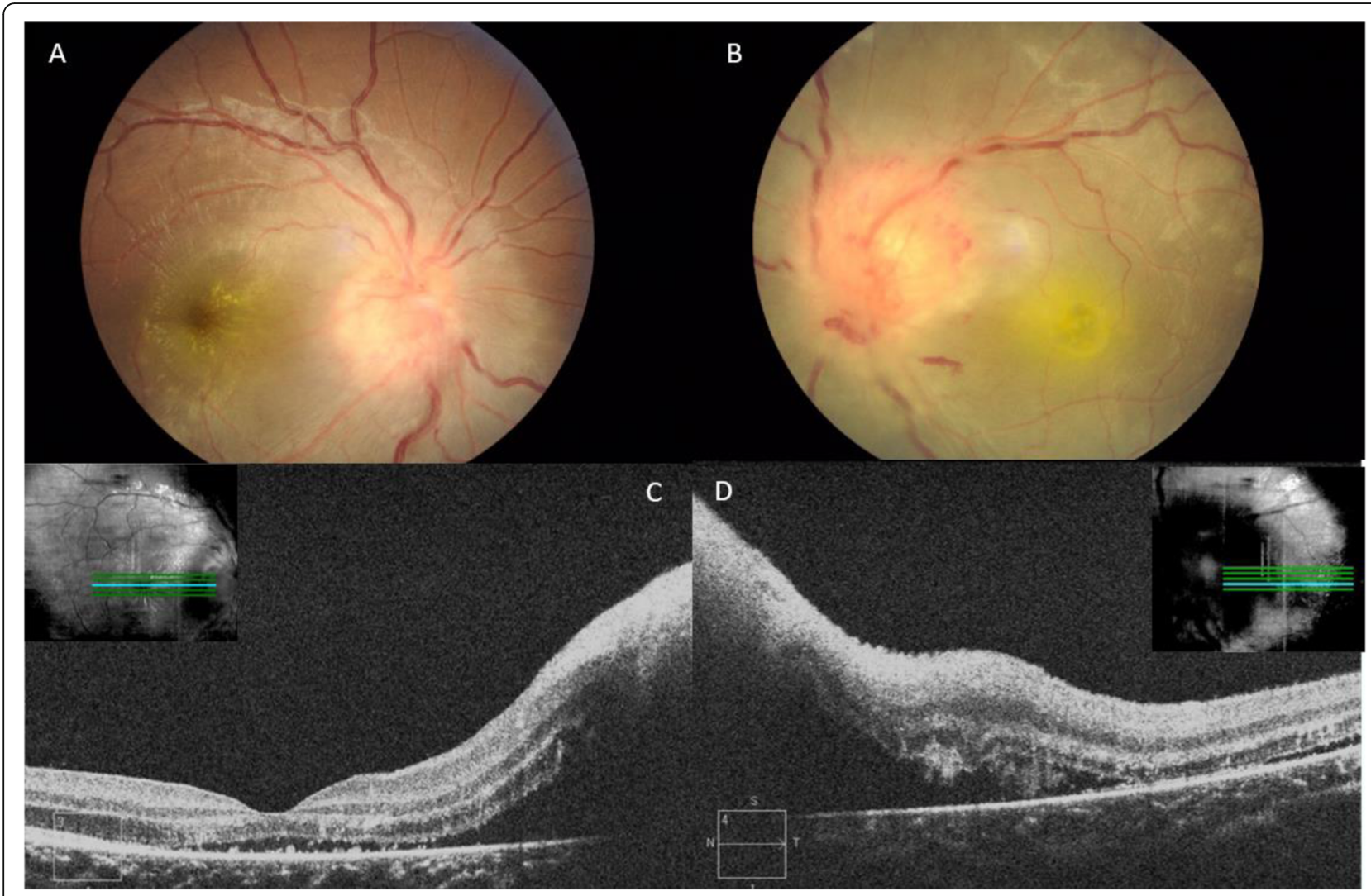

Fig. 4 Patient no 6. a and $\mathbf{b}$ Colour fundus photograph of the right and left eye respectively: both eyes have optic disc oedema with yellowish macular exudation (forming bilateral neuroretinitis) and also marked venous engorgement and tortuosity. $\mathbf{c}$ and $\mathbf{d}$ Corresponding SD-OCT macula of the right eye and left eye: fluid tracking from the oedematous optic disc to the subretinal space. Left eye especially, exhibits a loss of the normal foveal contour and marked serous macular detachment 
without macular star throughout the follow-up period. This particular patient was also the only one who manifested subclinical vitritis as evident on the SD-OCT image (Fig. 5), besides having the typical small foci of white retinal infiltrates in that same eye. Other possible infections like toxoplasmosis, syphilis, tuberculosis and endogenous endophthalmitis were ruled out in this particular patient. Thus, the absence of a neuroretinitis (or in this case, an optic disc swelling without macular involvement) does not safely exclude the possibility of ocular bartonellosis. Likewise, when a patient presents with injected conjunctivae and granulomatous follicular conjunctivitis, one should consider the possible diagnosis of Parinaud's oculoglandular syndrome, particularly if the patients had reported contact with cats or kittens. In our series, we report 3 patients who presented with Parinaud's oculoglandular syndrome (Fig. 3a-c). All of them had fever prior to their ocular symptoms and all had palpable enlargement of the ipsilateral cervical lymph nodes. Hence, examining patients' cervical lymph nodes for lymphadenopathy and exploring symptoms of preceding fever and systemic symptoms may aid in diagnosing Parinaud's oculoglandular syndrome. It is also worth noting that patients with Parinaud's oculoglandular syndrome were of the younger age group in our series, between 11 and 15 years old. Parinaud's oculoglandular syndrome is a frequently-missed diagnosis and likely remains significantly under-reported [20]. Patients may not seek treatment due to the self-limiting nature of the disease, good response to empirical antibiotic treatment and little effect on vision as compared to the posterior segment presentations. In our series, all 3 patients with Parinaud's oculoglandular syndrome had complete resolution of symptoms by the end of their follow-up visit. Ocular manifestation of vaso-occlusive events like retinal artery or retinal vein occlusions were reported in some studies, but none of our patients had such presentation $[1,5,18]$. Anterior segment inflammation has also been described $[13,21]$. Nevertheless, it did not occur in any of our patients. Patients who had posterior segment manifestations in our series showed typical macular changes on SD-OCT which includes hyperreflective foci within the retinal nerve fibre layer (RNFL) (retinitis spots clinically), hyperreflective foci of retinal exudates within the OPL (hard exudates clinically), presence of SRF tracking from the swollen $\mathrm{ONH}$ to the sub-foveal space (exudative retinal detachment at the sub-foveal/ macular region) and IRF causing retinal thickening and loss of foveal contour (Figs. 1d, 2b, 4c-d and 6b, d).

Antimicrobial treatment for B. Hensalae infection in the immunocompetent individuals have been controversial and no clear definitive treatment recommendations exist $[8,9]$. The difficulty to establish a treatment recommendation is partly due to the Bartonella infection being generally self-limiting $[13,21]$. Prior reports have suggested that early antimicrobial treatment may speed recovery and improve the final visual outcome [21, 22]. In our study, most patients (92.3\%) were treated with systemic antimicrobial, except for patient no. 9 as she was initially treated as ocular tuberculosis as her Mantoux test was borderline. She developed stellate macula exudates later on in association with optic disc oedema,

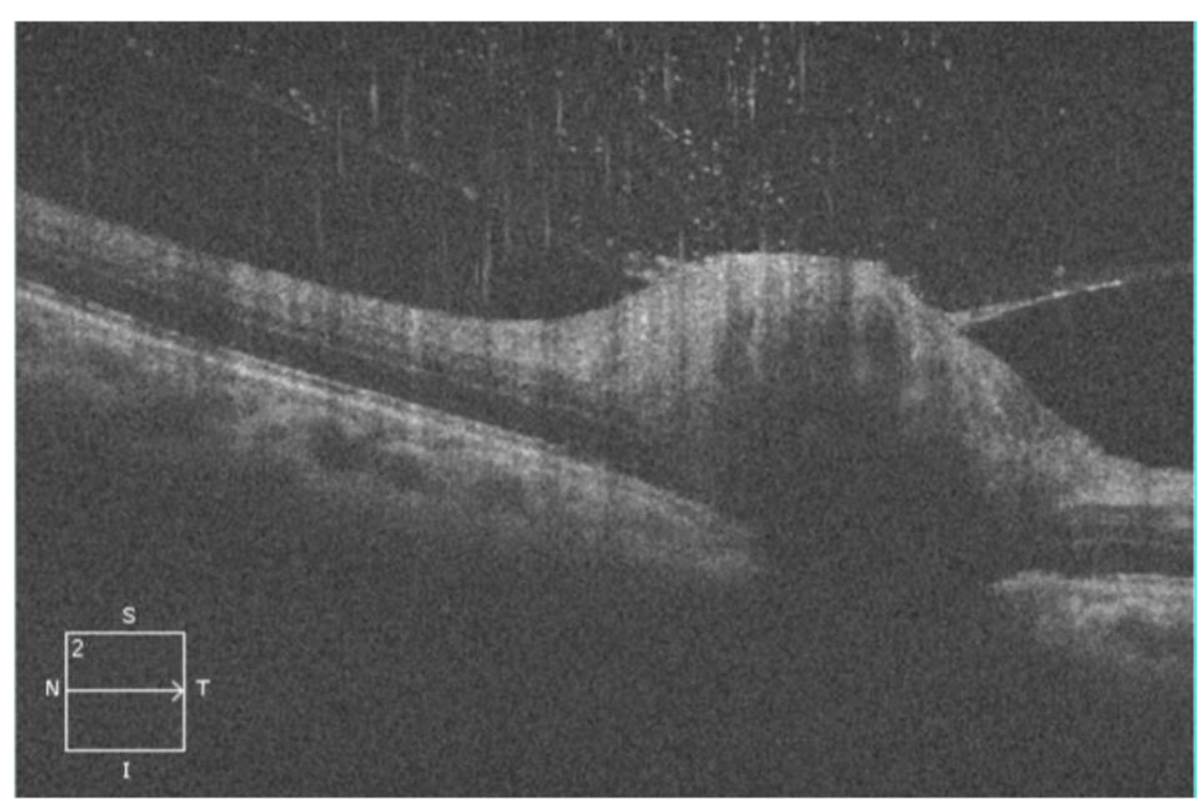

Fig. 5 Patient no. 12. SD-OCT of the left eye: swollen ONH with overlying vitritis and incomplete posterior vitreous detachment (PVD). No SRF or macula star developed in this patient. The $\mathrm{ONH}$ oedema and vitritis resolve following treatment 


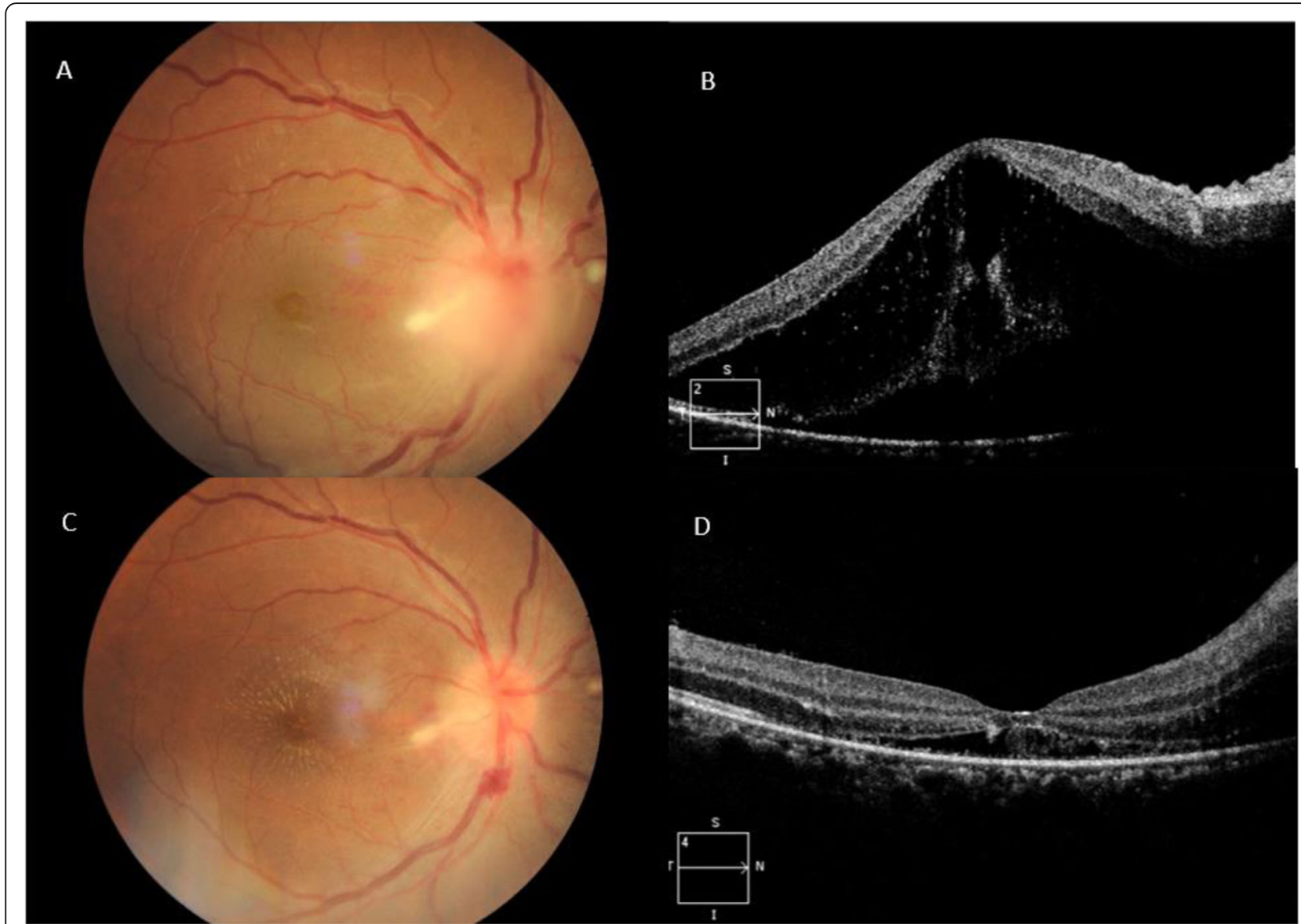

Fig. 6 Patient no. 7. a Colour fundus photograph of the right eye on initial presentation: swollen optic disc, macula oedema, peripapillary RNFL haemorrhages, yellow-white deep retinal lesions near the disc and venous engorgement. VA was 1/60. b Corresponding SD-OCT of the right eye: prominent IRF and SRF with loss of foveal contour. c Colour fundus photograph of the same eye after 2 weeks: resolving optic disc oedema and decrease in venous engorgement and tortuosity. $\mathbf{d}$ Corresponding SD-OCT of the same eye 2 weeks later: restoration of the foveal contour, IRF has resorbed with some residual SRF. VA improved to $6 / 18$

which raised the suspicion of Bartonella infection and this was confirm by a 4-fold increase in B. Hensalae serology titres on repeated testing. However, by the time the second serology result was available, her vision has already improved to 6/9, hence antibiotic treatment was not commenced. Rifampicin, gentamicin, cotrimoxazole, ciprofloxacin, and doxycycline have shown efficacy in the treatment of bartonella infection [21]. Some have reported azithromycin as the preferred antimicrobial of choice in treating ocular bartonellosis as it has better compliance, easier once daily dosing and better safety profile compared to doxycycline which is given twice a day and tends to cause gastrointestinal upset [22]. Also, azithromycin is also the only agent studied in a randomized controlled study for CSD [22]. Nevertheless, doxycycline continued to be used widely for the treatment of ocular bartonellosis in many centres and in our series, doxycycline is used most frequently, in $61.5 \%$ of patients. This is in part due to the ability of doxycycline to adequately penetrate the tissues of the eye and central nervous system and also since it is more widely available in our hospital setting [9]. The role of systemic corticosteroids is also debatable and not clearly established, often used in those with very poor vision on presentation. The association between visual outcome and systemic corticosteroids use was reported in a few studies. Chi et al. (2016) reported no association between systemic corticosteroids use and visual outcome [5] . Meanwhile, a multicentre retrospective cohort study by Habot-Wilner Z et al. (2011) reported that combined antimicrobial and systemic corticosteroids treatment was associated with a better visual outcome than regimen of antibiotics alone in patients with VA worse than $6 / 9$ at presentation [18]. In a case series of 14 patients in Japan reported by Kodoma et al, 13 of them received systemic steroids and 2 of them were treated with $1000 \mathrm{mg}$ of methylprednisolone pulse therapy [23]. In our series, systemic corticosteroids were commenced in patients 
who had significantly poor vision on presentation, i.e. VA of $6 / 60$ or less. Overall, 16 eyes (88.9\%) achieved a VA of $6 / 12$ or better at final follow-up visit. One patient had a final VA of 6/60 due to an atrophic macula following resolution of SRF in the same area and another one had a final VA of 6/18 due to residual macula star (the patient did not turn up for her subsequent follow-up visit after the 6th week and we were unable to ascertain whether the VA continue to improved later on).

There are few limitations to our study. Firstly, a second sample of serology should ideally be sent 2 weeks after the initial sample, as a 4-fold increase in titer is a definite diagnostic of $B$. Hensale infection. In our series, only two patients (patient no. 9 and patient no. 12) had a second Bartonella serology sample taken. In our clinical setting, a second sample is not usually taken as the results generally take up to 6 weeks. Most patients would have already responded to the treatment given or their symptoms may have resolved spontaneously by then. Therefore, further testing neither have aided in diagnosis nor altered clinical decision making. Also, some of the patients presented late to the clinic, and as such had missed the optimum window period for testing that would yield peak blood levels of IgM and IgG. In IFA, IgM positivity has been reported to decrease after 8 weeks while IgG positivity peaked after $6-8$ weeks. In addition, the IFA used in our bacteriology unit measures antibodies to both Bartonella henselae and Bartonella quintana; therefore, we were unable to differentiate between these Bartonella spp. infections. The polymerase chain reaction test is an alternative method to test for the Bartonella spp. and is highly sensitive but is not routinely done in our hospital setting due to the cost involved [24]. Secondly, it must be remembered that the true frequency of the ocular findings in ocular bartonellosis might differ from our results due to the small sample size of our study. Nevertheless, the main purpose of this study is not to precisely quantify the true incidence of each finding but rather to highlight some of the less, well appreciated clinical findings of ocular bartonellosis. Thirdly, this study was not able to establish association between antibiotics and corticosteroids use and visual outcome due to the retrospective design and lack of control group arm. In order to determine whether antibiotics and corticosteroids treatment is helpful in improving VA in patients who present with ocular manifestations of Bartonella infection, a randomized clinical trial comparing a standardized treatment regimen to placebo will be necessary.

\section{Conclusion}

Small foci of retinal white lesions were the most common ocular manifestation of ocular bartonellosis in this study, followed by neuroretinitis, though patients can also present with other ocular signs as described above. Most of the patients who were affected were immunocompetent, had bilateral eye involvement and had fever prior to their ocular presentations. The visual prognosis of ocular bartonellosis is generally good.

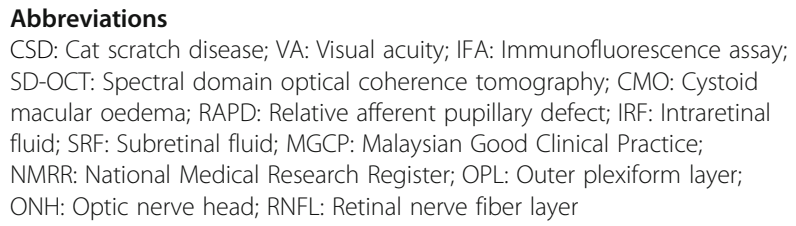

\section{Acknowledgements}

We would like to thank the Director General of Health Malaysia for his permission to publish this article. We also would like to express our gratitude to the Ophthalmology department of Hospital Sultanah Aminah Johor Bahru, and those who had extended their help in contributing to this manuscript.

\section{Authors' contributions}

MSYT carried out the date collection, literature search and writing of the manuscript. GG and FMV carried out critical revision and correction of the manuscript. All authors read and approved the final manuscript for submission and publication.

\section{Funding}

This study was conducted without any funding from any parties.

Availability of data and materials

Please contact authors for data requests.

\section{Ethics approval and consent to participate}

This work adheres to the guidelines and principles by the Declaration of Helsinki and is in accordance to the Malaysian Good Clinical Practice (MGCP) 4th edition 2018. This research is also registered with the National Medical Research Register (NMRR) and ethics approval was obtained from the Medical Research and Ethics Committee (MREC) prior to the initiation of the study.

Consent for publication

Not applicable.

\section{Competing interests}

The authors declare that they have no competing interests.

Received: 19 March 2020 Accepted: 27 October 2020

Published online: 16 November 2020

\section{References}

1. Solley WA, Martin DF, Newman NJ, King R et al (1999) Cat scratch disease: posterior segment manifestations. Ophthalmology 106:1546-1553

2. Rolain JM, Brouqui P, Koehler JE et al (2004) Recommendations for treatment of human infections caused by Bartonella species. Antimicrob Agents Chemother 48:1921-1933

3. Amelia A, Lakanakumar T, Shatriah I et al (2015) Cat scratch disease presenting as increased intracranial pressure and aseptic meningitis. Asian Pac J Trop Med 5(6):500-501

4. Florin TA, Zaoutis TE, Zaoutis LB (2008) Beyond cat scratch disease: widening spectrum of Bartonella henselae infection. Pediatrics 121:e1413e1425

5. Chi SL, Stinnett S, Eggenberger E et al (2012) Clinical characteristics in 53 patients with cat scratch optic neuropathy. Ophthalmology 119(1):183-187

6. Bar S, Segal M, Shapira R et al (1990) Neuroretinitis associated with cat scratch disease. Am J Ophthalmol 110:703-705

7. Zacchei AC, Newman NJ, Sternberg P (1995) Serous retinal detachment of the macula associated with cat scratch disease. Am J Ophthalmol 120:796-797

8. Ormerod LD, Dailey JP (1999) Ocular manifestations of cat-scratch disease. Curr Opin Ophthalmol 10:209-216 
9. Cunningham ET, Koehler JE (2000) Ocular Bartonellosis. Am J Ophthalmol 130:340-349

10. Barros S, de Andrade GC, Cavalcanti C et al (2018) Cat scratch disease: not a benign condition. Ocul Immunol Inflamm 26(7):1115-1122

11. Lee WR, Chawla JC, Reid R (1994) Bacillary angiomatosis of the conjunctiva. Am J Ophthalmol 118:152-157

12. Curi AL, Machado D, Heringer G et al (2010) Cat-scratch disease: ocular manifestations and visual outcome. Int Ophthalmol 30:553-558

13. Tan CL, Fhun LC, Tai EL et al (2017) Clinical profile and visual outcome of ocular Bartonellosis in Malaysia. J Trop Med 2017:7946123

14. Koehler JE, Glaser CA, Tappero JW (1994) Rochalimaea henselae infection. A new zoonosis with the domestic cat as a reservoir J Am Med Assoc 271: 531-535

15. Wan M, Luu S (2017) Bilateral neuroretinitis due to Bartonella henselae in a child. Can J Ophthalmol 53(2):e69-e71

16. Metz CH, Buer J, Bornfeld N, Lipski A (2012) Bilateral Bartonella henselae neuroretinitis with stellate maculopathy in a 6-year-old boy. Infection. 40(2): 191-194

17. Wade NK, Levi L, Jones MR et al (2000) Optic disk edema associated with peripapillary serous retinal detachment: an early sign of systemic Bartonella henselae infection. Am J Ophthalmol 130(3):327-334

18. Habot-Wilner Z, Trivizki O, Goldstein M et al (2018) Cat-scratch disease: ocular manifestations and treatment outcome. Acta Ophthalmol 96(4): e524-e532

19. Dehio C (2004) Molecular and cellular basis of bartonella pathogenesis. Annu Rev Microbiol 58:365-390

20. Arjmand P, Yan P, O'Connor MD (2015) Parinaud Oculoglandular syndrome 2015: review of the literature and update on diagnosis and management. J Clin Exp Ophthalmol 6:443. https://doi.org/10.4172/2155-9570.1000443

21. Reed JB, Scales KD, Wong MT et al (1998) Bartonella henselae neuroretinitis in cat scratch disease: diagnosis, management, and sequelae. Ophthalmology 105:459-466

22. Bass JW, Freitas BC, Freitas AD et al (1998) Prospective randomized doubleblind placebo-controlled evaluation of azithromycin for treatment of catscratch disease. Pediatr Infect Dis J 17(6):447-452

23. Kodama T, Masuda H, Ohira A (2003) Neuroretinitis associated with catscratch disease in Japanese patients. Acta Ophthalmol Scand 81:653-657

24. Diniz PP, Velho PE, Pitassi LH et al (2016) Risk factors for Bartonella species infection in blood donors from Southeast Brazil. PLoS Neglected Tropical Diseases 10(3):e0004509

\section{Publisher's Note}

Springer Nature remains neutral with regard to jurisdictional claims in published maps and institutional affiliations.

\section{Submit your manuscript to a SpringerOpen ${ }^{\circ}$ journal and benefit from:}

- Convenient online submission

- Rigorous peer review

- Open access: articles freely available online

- High visibility within the field

- Retaining the copyright to your article

Submit your next manuscript at $\boldsymbol{\nabla}$ springeropen.com 